\title{
Chemically modified cellulose micro- and nanofibrils as paper-strength additives
}

\author{
Rebecca Hollertz $\mathbb{D}$ - Verónica López Durán · Per A. Larsson • Lars Wågberg
}

Received: 27 February 2017 / Accepted: 22 June 2017 / Published online: 29 June 2017

(C) The Author(s) 2017. This article is an open access publication

\begin{abstract}
Chemically modified cellulose micro- and nanofibrils were successfully used as paper strength additives. Three different kinds of cellulose nanofibrils (CNFs) were studied: carboxymethylated CNFs, periodate-oxidised carboxymethylated CNFs and dopamine-grafted carboxymethylated CNFs, all prepared from bleached chemical fibres of dissolving grade, and one microfibrillated cellulose from unbleached kraft fibres. In addition to mechanical characterization of the final paper sheets the fibril retention, sheet density and sheet morphology were also studied as a function of addition of the four different cellulose fibrils. In general, the cellulose fibrils, when used as additives, significantly increased the tensile strength, Young's modulus and strain-atbreak of the paper sheets. The effects of the different fibrils on these properties were compared and
\end{abstract}

Electronic supplementary material The online version of this article (doi:10.1007/s10570-017-1387-6) contains supplementary material, which is available to authorized users.

R. Hollertz $(\bowtie)$ · V. L. Durán · P. A. Larsson ·

L. Wågberg $(\bowtie)$

Fibre and Polymer Technology, KTH Royal Institute

of Technology, 10044 Stockholm, Sweden

e-mail: rhollert@kth.se

L. Wågberg

e-mail: wagberg@kth.se

V. L. Durán · P. A. Larsson · L. Wågberg

BiMaC Innovation, KTH Royal Institute of Technology,

10044 Stockholm, Sweden evaluated and used to analyse the underlying mechanisms behind the strengthening effect. The strengthenhancing effect was most pronounced for the periodate-oxidised CNFs when they were added together with polyvinyl amine (PVAm) or poly(dimethyldiallylammonium chloride) (pDADMAC). The addition of periodate-oxidised CNFs, with pDADMAC as retention aid, resulted in a $37 \%$ increase in tensile strength at a $2 \mathrm{wt} \%$ addition and an $89 \%$ increase at a $15 \mathrm{wt} \%$ addition (from 67 to 92 and $125 \mathrm{kNm} / \mathrm{kg}$, respectively) compared to a reference with only pDADMAC. Wet-strong sheets with a wet tensile index of $30 \mathrm{kNm} / \mathrm{kg}$ were also obtained when periodate-oxidised CNFs and PVAm were combined. This significant increase in wet strength is suggested to be the result of a formation of cross-links between the aldehyde groups, introduced by the periodate oxidation, and hydroxyl groups on the lignocellulosic fibres and the primary amines of PVAm. Even though less significant, there was also an increase in wet tensile strength when pDADMAC was used together with periodate-oxidised fibrils which shows that the aldehyde groups are able to increase the wet strength without the presence of the primary amines of the PVAm. As an alternative method to strengthen the fibre network, carboxymethylated CNFs grafted with dopamine, by an ethyl dimethylaminopropyl carbodiimide coupling, were used as a strength additive. When used as an additive, these CNFs showed a strong propensity to form films on and around the fibres and 
significantly increased the mechanical properties of the sheets. Their addition resulted in an increase in the Younǵs modulus by $41 \%$, from 5.1 to $7.2 \mathrm{GPa}$, and an increase in the tensile strength index of $98 \%$ (from 53 to $105 \mathrm{kNm} / \mathrm{kg}$ ) with $5 \mathrm{wt} \%$ retained dopaminegrafted CNFs.

Keywords Carboxymethylation - Cellulose nanofibrils · Dopamine grafting · Periodate oxidation · Paper strength $\cdot$ Strength additives

\section{Introduction}

Microfibrillation of lignocellulosic fibres to produce microfibrillated cellulose (MFC) was first reported by Turbak et al. (1983). However, it was not until the last decade that both scientific and industrial interest in this material accelerated. Among the advantages of using micro- and nanofibrillated cellulose is that it is renewable, highly abundant, has excellent mechanical properties and a large specific surface area. Nowadays, cellulose fibres disintegrated into fibrils and particles with dimensions in the micro- and nanoscale, commonly referred to as nanocelluloses are divided into three different classes: cellulose nanofibrils (CNFs), $\mathrm{MFC}$ and cellulose nanocrystals (CNCs). Owing to the intriguing properties of CNFs, a variety of high-end applications have been proposed. The optical transparency and excellent mechanical properties of CNFs make them suitable in coating and packaging applications (Lavoine et al. 2014; Spoljaric et al. 2014; Azeredo et al. 2015; Kumar et al. 2016). Flexible screens (Okahisa et al. 2009), supercapacitors and batteries (Hamedi et al. 2013; Nyström et al. 2015) are also among the applications for which nanocelluloses have been suggested. The use of nanocellulose in composites has also been extensively studied and a comprehensive review by Berglund et al. (2010) summarises the promising development in this area. As a natural consequence of their origin, there is also an interest in using CNFs in bulk materials such as paper and paperboard. In papermaking, CNFs can be used as an additive to obtain a specific functionality without the need to modify the entire fibre furnish. Previous studies have shown a positive effect of CNFs and MFC additives on the strength of dry papers (Ahola et al. 2008; Eriksen et al. 2008; Hubbe et al. 2008; Taipale et al. 2010; Rezayati Charani et al.
2013; Brodin et al. 2014; Hietala et al. 2016). However, the addition of CNFs was also reported to increase the dewatering time and the density of the final paper (Taipale et al. 2010; Hietala et al. 2016). This means that if the densification of the sheet is the major effect of the CNF addition a beating of the fibres would most probably be a better alternative to CNF addition. It is hence of large importance to clarify exactly how the CNF addition will improve the sheet properties.

The tensile strength of paper sheets depends on various factors, such as fibre strength, fibre length, fibre orientation, fibre-fibre contact area and joint strength (Page 1969). CNFs have properties comparable to those of dry strength additives and of small fibre fragments, i.e. fines, since in both cases the fibrefibre contact area in the sheet is increased (Wågberg and Björklund 1993a). This is also what is achieved by beating, which also increases the content of fines. The covering of the fibre surfaces with a thin CNF layer could improve the fibre-fibre contact on a molecular level during and after drying. Furthermore, CNFs may possibly fill the voids and pores at the edges of each fibre joint, thus extending the contact area of each fibre-fibre joint. The joint strength could also be increased by introducing covalent bonds in the fibrous network. The hypothesis is that this approach is essential for improving both wet and dry strength.

In previous studies using fibrils as strength additives, different types of CNFs or MFCs have been used in combination with different types of lignocellulosic fibres. It is therefore difficult to quantitatively compare the effect that different CNFs have on the properties of the papers made from a specific fibre furnish. The aim of this work was to study the effect of three different CNFs and one MFC on the dry and wet mechanical properties of the final paper. In this study we compared the effect of unbleached softwood kraft MFC, carboxymethylated CNFs, periodate-oxidised carboxymethylated CNF and dopamine-grafted carboxymethylated CNFs. The fibrils were mixed directly into the fibre furnish, an unbleached softwood kraft pulp, with and without further addition of a retention aid since the self-retention of the cellulose fibrils is considered to be an important inherent property. The tensile properties of the prepared laboratory handsheets were measured and evaluated with respect to the amount of the fibrils in the sheet, the density of the sheets and the sheet morphology. 
The softwood kraft MFC was produced from unbleached kraft pulp and was only subjected to mechanical treatment; through beating followed by homogenization. The carboxymethylated fibrils were prepared from fully bleached wood-fibres to introduce more charges and thereby facilitate the liberation of nanofibrils, providing more well dispersed and liberated fibrils. The periodate-oxidised carboxymethylated CNFs were used since the dialdehydes formed from the cleaved $\mathrm{C} 2-\mathrm{C} 3$ bond (Jackson and Hudson 1937), can cross-link with the hydroxyls of unmodified cellulose on fibres, or fibrils, to form hemiacetal linkages (Zeronian et al. 1964; Weatherwax and Caulfield 1978; Larsson et al. 2008, 2013) which have shown to significantly improve the wet strength of paper (Stamm 1959; LeBel et al. 1968). These aldehydes can also be used for further conversion or attachment of other functional groups is possible (Fessenden and Fessenden 1986). Finally, an alternative approach to obtain wet strength, using dopamine-grafted CNFs, was used according to earlier investigations by (Karabulut et al. 2012) where films made from these fibrils exhibited wet stability with a significant wet adhesion. Dopamine or 3,4-dihydroxyphenylalanine is a catecholamine produced by marine mussels. Under alkaline conditions, the catechol can be oxidised to quinone, which allows the dopamine to self-polymerize and form thin films through a combination of covalent bond formation and other molecular interactions such as hydrogen bonding, metal chelation and $\pi-\pi$ interactions. Research on dopamine-modified materials is inspired by the important role that dopamine plays for the outstanding mechanical stability of the wet mussel byssus (Lee et al. 2006, 2007b). To the best knowledge of the authors, there are no publications regarding the use of dopamine-grafted CNFs as paper additives to achieve improved strength.

\section{Materials and methods}

\section{Materials}

An electrical grade unbleached kraft pulp (Munksjö, Aspa Bruk, Sweden) was used to produce laboratory handsheets. Sodium metaperiodate $(99.8 \%)$ was purchased from Alfa Asear. Hydroxylamine hydrochloride
(99\%), dopamine hydrochloride, poly(dimethyldiallylammonium chloride (pDADMAC) with a molecular weight of $400-500 \mathrm{kDa}$ and 1-ethyl-3-(3-dimethylaminopropyl)carboiimide (EDC) were purchased from Sigma Aldrich and were used without further modification. Polyvinylamine (PVAm), with a molecular weight of $340 \mathrm{kDa}$ was obtained from BASF and used as received. Deionised water was used throughout the study unless otherwise indicated.

\section{Methods}

\section{Pre-treatment of the pulp}

The fibres were beaten in a PFI-mill for 4000 revolutions and then washed and transferred to their sodium form according to a previously described procedure (Wågberg and Björklund 1993b).

\section{Preparation of carboxymethylated CNFs}

Sulphite softwood dissolving pulp (Aditya Birla Domsjö Fabriker AB, Örnsköldsviks, Sweden) from $60 \%$ Norwegian spruce and $40 \%$ Scots pine was used to prepare carboxymethylated cellulose fibres according to a previously described procedure (Wågberg et al. 2008). Carboxymethylated CNFs were prepared at RISE Bioeconomy, Stockholm, Sweden by homogenisation of the pre-treated fibres. The fibres were then defibrillated using a Microfluidizer M-110eh (Microfluidics Inc., USA) with a pair of chambers connected in series. The first two passes were made, with a pressure of 900 bar, through 400 and $200 \mu \mathrm{m}$ diameter chambers, followed by three passes, with a pressure of 1500 bar, through 200 and $100 \mu \mathrm{m}$ chambers. The final $\mathrm{CNF}$ concentration after fluidization was $2.0 \mathrm{wt} \%$.

\section{Periodate oxidation of carboxymethylated CNFs}

Carboxymethylated CNFs were diluted to $1.5 \mathrm{wt} \%$ and $0.7 \mathrm{~g}$ sodium periodate/g CNFs was added to the dispersion. The mixture was then stirred for $5 \mathrm{~min}$ using an Ultra Turrax mixer (IKA, T25 Basic, Staufen, Germany) at $12,000 \mathrm{rpm}$. After $24 \mathrm{~h}$ at room temperature, in the dark to limit chain cleavage due to radical formation, the periodate-oxidised CNFs were purified by dialysis for 3 days. The amount of aldehyde formed after periodate oxidation was determined by reaction with hydroxylamine hydrochloride (Zhao and Heindel 
1991; Larsson et al. 2008). In brief, $20 \mathrm{~mL}$ of $0.25 \mathrm{M}$ hydroxylamine solution was mixed with $25 \mathrm{~mL}$ of the periodate-oxidised CNFs, both set to $\mathrm{pH} \mathrm{4}$, and allowed to react for $2 \mathrm{~h}$. When hydroxylamine hydrochloride reacts with aldehyde an oxime is produced and one equivalent of $\mathrm{HCl}$ is released, which consequently reduces the $\mathrm{pH}$. The $\mathrm{pH}$ of the solution was then titrated back to $\mathrm{pH} 4$ using $0.10 \mathrm{M}$ sodium hydroxide. The solution was thereafter dried in an oven at $105{ }^{\circ} \mathrm{C}$ to determine the dry mass of CNFs, the weight of the hydroxylamine being subtracted when the total dry mass of CNFs was determined. Carbonyl determinations were performed in duplicate.

\section{Dopamine-grafted CNFs}

Dopamine was grafted to carboxymethylated CNFs according to a previously described procedure using EDC as a coupling agent (Karabulut et al. 2012). The CNF suspension was diluted to $0.7 \mathrm{~g} / \mathrm{L}$ using phosphate-buffered saline solution, and set to $\mathrm{pH} 5$ using $\mathrm{HCl}$. CNFs and EDC were mixed for one minute before addition of dopamine; the molar ratio of dopamine:COOH was 0.5:1.0 and the EDC:dopamine molar ratio was 1.67:1.0. The mixture was left to react for $6 \mathrm{~h}$ at room temperature. Unreacted dopamine and EDC was removed by dialysis for 6 days ( 2 days in Milli-Q water at pH 5 and 4 days in Milli-Q water at $\mathrm{pH} 7$ ). The conductivity of the dialysis water after 6 days was below $5 \mu \mathrm{S} / \mathrm{cm}$.

Figure 1 shows the chemical structures of the functional groups of the differently modified CNFs.

\section{Kraft MFC preparation}

Kraft MFC, from the electrical-grade unbleached kraft pulp, was prepared by beating the pulp for a total of 6000 revolutions in a PFI- mill and then fluidizing it in a Microfluidizer M-110eh (Microfluidics Inc., USA) by three passes through a $400 \mu \mathrm{m}$ and a $200 \mu \mathrm{m}$ chamber at a pressure of 900 bar connected in series followed by three passes at 1500 bar through a $200 \mu \mathrm{m}$ and a $100 \mu \mathrm{m}$ chamber connected in series.

\section{Total charge density determination}

The total charge density of the fibres was determined according to SCAN-CM 65:02 by conductometric titration using a Metrohm 702SM Titrino titrator. Before titration the $\mathrm{pH}$ of the fibre suspension was set to $\mathrm{pH} 2$, in order to change the counterions to proton form. Then, $0.2 \mathrm{~g}$ of fibres were placed in a glass container with $10 \mathrm{~mL}$ of $0.1 \mathrm{M} \mathrm{NaCl}, 5 \mathrm{~mL}$ of $\mathrm{HCl}$ $0.01 \mathrm{M}$ and water to a total volume of $500 \mathrm{~mL}$ and titrated using $0.1 \mathrm{M} \mathrm{NaOH}$ under a continuous flow of $\mathrm{N}_{2}$.

\section{Surface charge density determination}

The surface charge of the CNFs was determined by polyelectrolyte titration with streaming potential measurements using a Stabino particle charge mapping equipment (ParticleMetrix, Germany). A $0.1 \mathrm{wt} \% \mathrm{CNF}$ dispersion was prepared and $0.5 \mathrm{~mL}$ dispersion was thereafter dispersed to a total volume

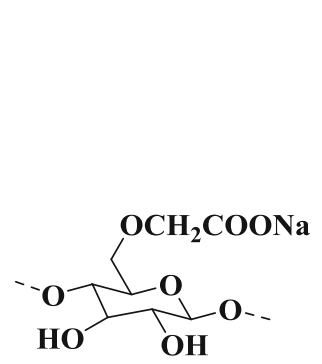

(a)

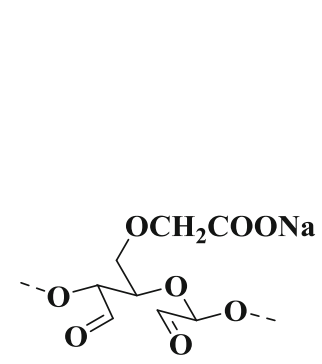

(b)

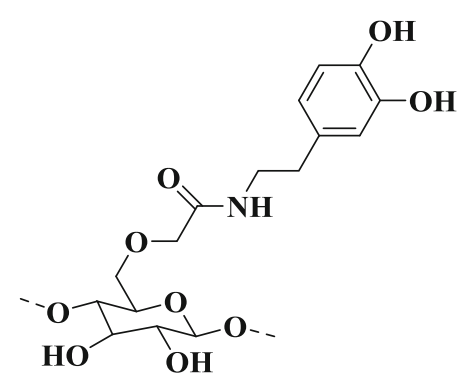

(c)

Fig. 1 Chemical structures of the functional groups of: a carboxymethylated CNFs, b periodate-oxidised carboxymethylated CNFs and $\mathbf{c}$ dopamine-grafted carboxymethylated CNFs 
of $10 \mathrm{~mL}$ and titrated with pDADMAC with a molecular weight of 400-500 kDa and a total charge of $0.227 \mu \mathrm{eq} / \mathrm{mL}$. At least three replicates were performed for each sample.

\section{Nitrogen analysis}

Total nitrogen content analysis was performed in an ANTEK 7000 Model (ANTEK instruments Inc., USA). A solution of $1 \mathrm{~g} / \mathrm{L}$ of dopamine hydrochloride was prepared and different volumes $(5,10,15,20$ and $25 \mu \mathrm{L}$ ) of the solution were injected in the instrument to prepare a calibration curve. Thereafter, samples of 5-10 mg were taken from the dopamine-grafted CNF film and inserted. The total nitrogen content was calculated using the calibration curve.

\section{Laboratory handsheet preparation}

Two series of handsheets, with three different added amounts of CNFs and MFC (2, 5 and $15 \mathrm{wt} \%$ of the total dry weight) were prepared for each of the above described types: one with PVAm as retention aid and one without retention aid. The preparation procedure and test series are further described in Fig. 2. PVAm, $2.5 \mathrm{mg} / \mathrm{g}$ fibres, was adsorbed at $\mathrm{pH} 8$ at a pulp concentration of $5 \mathrm{~g} / \mathrm{L}$. The polyelectrolyte addition corresponds to an equilibrium concentration obtained from the adsorption isotherm at $\mathrm{pH} 8$ (supporting information). The isotherm was obtained as described by (Wågberg et al. 1989). The pulp-polyelectrolyte suspension was rinsed by filtration using deionised water until the conductivity of the filtrate was below $5 \mu \mathrm{S} / \mathrm{cm}$. The periodate-oxidised CNFs were also used together with $2 \mathrm{mg} / \mathrm{g}$ pDADMAC added, as retention aid. Before addition the CNF suspension was diluted to $1 \mathrm{~g} / \mathrm{L}$, and mixed in an Ultra Turrax disperser for $20 \mathrm{~min}$ at $10,000 \mathrm{rpm}$, prior to addition to the fibre suspension. The CNFs were then added to a pulp suspension with a concentration of $2.5 \mathrm{~g}$ fibres/L. Handsheets with a target grammage of $80 \mathrm{~g} / \mathrm{m}^{2}$ were prepared with the aid of a Rapid Köthen sheet former (Paper Testing Instruments, Austria) and dried for $15 \mathrm{~min}$ at a temperature of $93{ }^{\circ} \mathrm{C}$ and a reduced

(a)
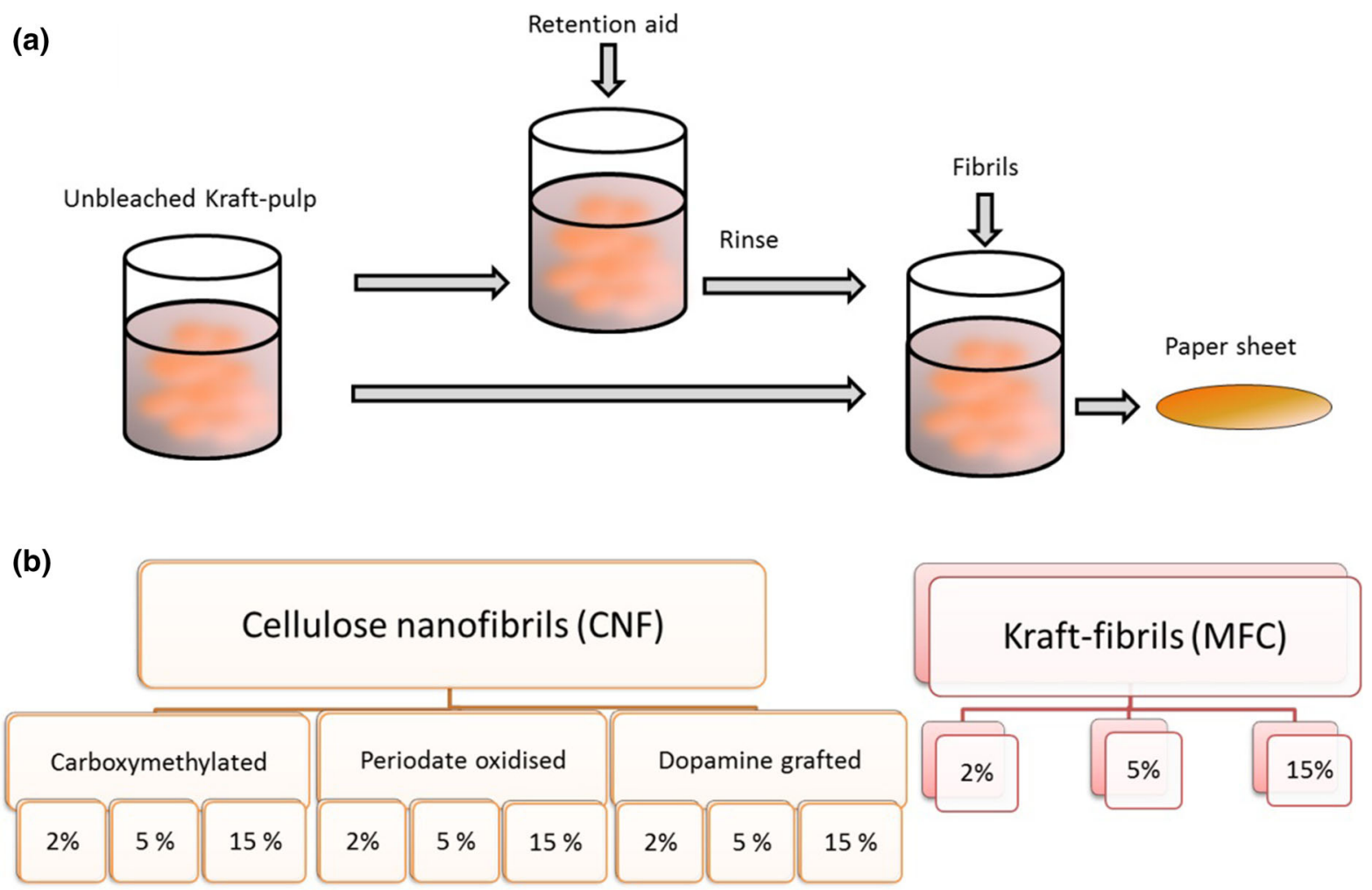

Fig. 2 a Preparation procedure of sheets with and without retention aid. b Chart summarising the CNF types and the added amounts of $\mathrm{CNF}(\mathrm{wt} \%)$ 
pressure of $95 \mathrm{kPa}$. The sheets were weighed directly after drying to estimate the retention of the CNFs added.

\section{Film preparation}

Periodate-oxidised CNFs diluted to $5 \mathrm{~g} / \mathrm{L}$ were dispersed for $10 \mathrm{~min}$ at $15,000 \mathrm{rpm}$ using an IKA UltraTurrax disperser and then vacuum filtered using a $0.45 \mu \mathrm{m}$ Durapore membrane filter (Merck Millipore Ltd.). After filtration, another membrane was placed on top of the wet film, and the assembly was dried using the Rapid Köthen sheet former for $15 \mathrm{~min}$ at $93{ }^{\circ} \mathrm{C}$ under a reduced pressure of $95 \mathrm{kPa}$. Two films of periodate-oxidised CNFs with retention aids, one with PVAm and one with pDADMAC, were also prepared. The periodate-oxidised CNFs were added to an aqueous solution containing $2 \mathrm{mg} / \mathrm{g}$ CNFs of PVAm or $2.5 \mathrm{mg} / \mathrm{g}$ CNFs of pDADMAC. The films were stored at $23{ }^{\circ} \mathrm{C}$ and $50 \% \mathrm{RH}$ prior to mechanical testing.

\section{Mechanical testing}

Prior to tensile testing, the thickness of the samples was determined according to SCAN-P 88:01. Tensile testing was performed at $23{ }^{\circ} \mathrm{C}$ and $50 \% \mathrm{RH}$ using an Instron 5944 equipped with a $500 \mathrm{~N}$ load cell. Strips with a width of $15 \mathrm{~mm}$ and a free span of $100 \mathrm{~mm}$ between the clamps were then strained at a constant rate of $100 \mathrm{~mm} / \mathrm{min}$. Five specimens per sample were tested. For wet tensile strength, the sheets were soaked in water for $1 \mathrm{~h}$ prior to tensile testing according to the SCAN-P 20:95 standard.

\section{SEM imaging}

The sheets containing CNFs were imaged under a scanning electron microscopy (Hitachi S-4800). Prior to imaging, the samples were coated with a $\sim 7 \mathrm{~nm}$ thick platinum/palladium coating in a 208 HR Cressington Sputter Coater.

\section{Results}

Characterization of fibres and fibrils used

The total and the surface charge density of the unbleached kraft fibres and the surface charge of the fibrils were measured. The fibres had a total charge density of $85 \mu \mathrm{eq} / \mathrm{g}$ and a surface charge density of $9 \mu \mathrm{eq} / \mathrm{g}$. The surface charges of the different CNFs are given in Table 1, which shows that the surface charge densities of periodate-oxidised CNFs and dopaminegrafted CNFs were lower than that of the original carboxymethylated CNFs. The surface charge of the periodate-oxidised and dopamine-grafted CNFs showed a considerable decrease compared with the carboxymethylated CNFs.

To characterize the yield of the coupling reaction, elemental analysis of nitrogen was performed, and it was found that $0.078 \mathrm{mmol} / \mathrm{g}$ of dopamine was attached to the carboxymethylated CNFs. To quantify the degree of modification of periodate-oxidised CNFs, the amount of aldehyde introduced was determined by a reaction with hydroxylamine hydrochloride. After $24 \mathrm{~h}$ of oxidation of carboxymethylated CNFs, $3.6 \mathrm{mmol}$ of aldehydes/g CNFs was observed (i.e. about $30 \%$ degree of oxidation).

\section{Retention of fibrils}

The retention of the different CNFs and of the MFC was studied with and without a retention aid (Fig. 3). In addition to PVAm, pDADMAC was used as an alternative retention aid to compare the interactions between the aldehydes on the periodate-oxidised CNFs and primary and quaternary amines, PVAm and pDADMAC respectively. The kraft MFC had a good retention and a linearly increasing amount was observed in the sheets with increasing addition; the carboxymethylated CNFs showed the poorest retention (only $18 \%$ of the added CNFs were retained at a $15 \mathrm{wt} \%$ addition). The dopamine-grafted CNFs had a lower retention than the periodate-oxidised CNFs, but a higher retention than the carboxymethylated CNFs. For the periodate-oxidised CNFs, the retention increased with increasing CNF content and reached over $90 \%$ at a $15 \mathrm{wt} \%$ addition.

\section{Morphology}

Already at low CNF additions ( $2 \mathrm{wt} \%$ ), fibril networks or films could be seen at the fibre joints, partly closing the pore openings formed between the fibres (see Supporting information). In the SEM images in Fig. 4 it is possible to observe coherent fibril networks (i.e. films) at the $15 \mathrm{wt} \%$ addition of CNFs. The dopamine- 
Table 1 Total and surface charge densities of fibrils

\begin{tabular}{lcc}
\hline Sample & $\begin{array}{l}\text { Total charge } \\
\text { density }(\mu \mathrm{eq} / \mathrm{g})\end{array}$ & $\begin{array}{c}\text { Surface charge } \\
\text { density }(\mu \mathrm{eq} / \mathrm{g})\end{array}$ \\
\hline Carboxymethylated CNFs & $576 \pm 4$ & $573 \pm 15$ \\
Periodate-oxidised CNFs & $483 \pm 9$ & $276 \pm 18$ \\
Dopamine-grafted CNFs & $435 \pm 10$ & $320 \pm 23$ \\
Kraft MFC & $85 \pm 6$ & $35 \pm 4$ \\
\hline
\end{tabular}
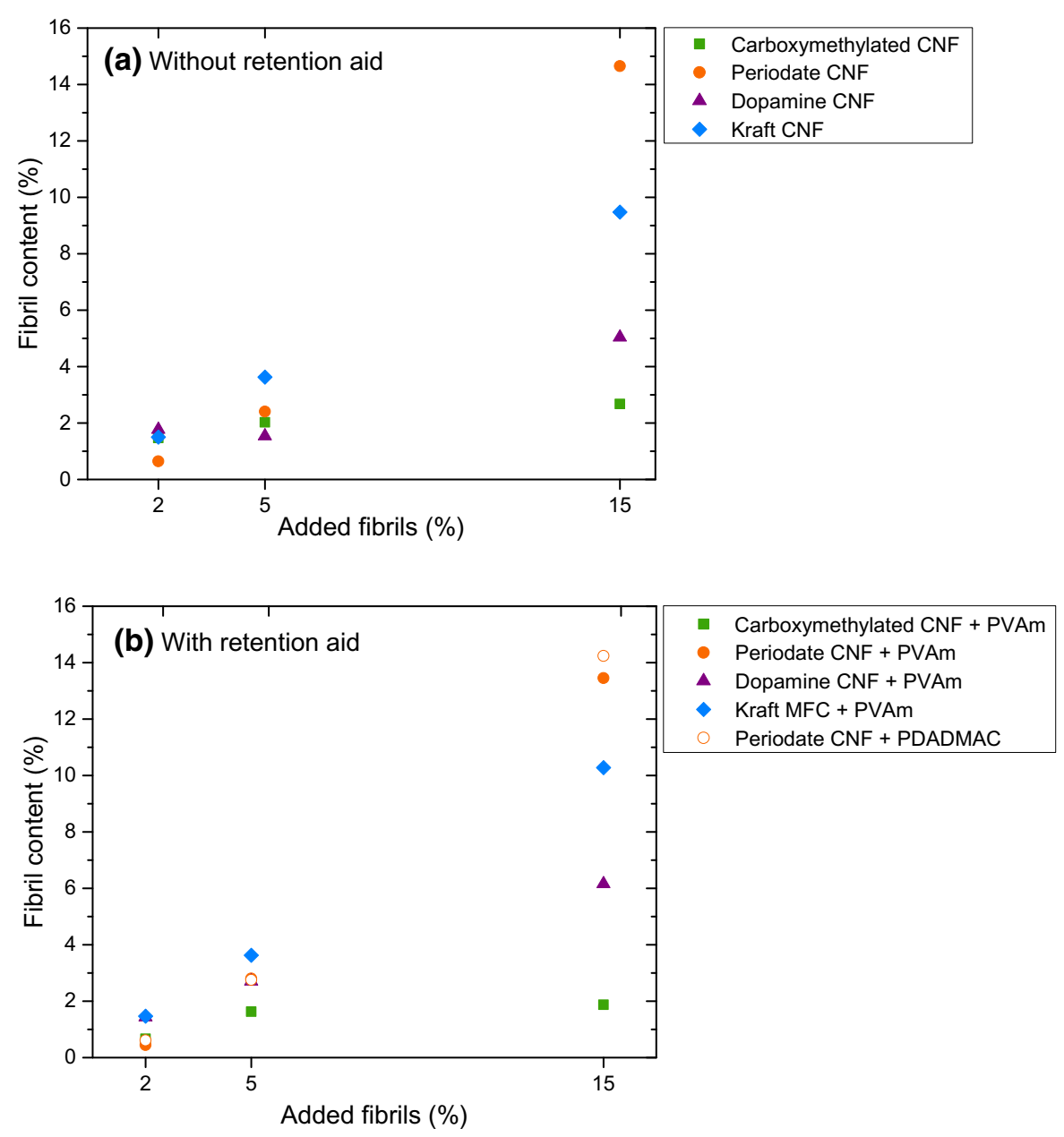

Fig. 3 a Estimated fibril content, gravimetrically determined, without any retention aid and b estimated fibril content with PVAm as retention aid. pDADMAC was also used as a retention aid together with the periodate-oxidised CNFs (open circles)

grafted CNFs show a strong tendency to form these films, but with periodate-oxidised CNFs, especially together with PVAm, the film formation takes place first at higher additions (Supporting information). The kraft MFC also forms films, even though the propensity is not as strong as for the dopamine-grafted CNFs. The carboxymethylated CNFs also form networks, but, due to the low retention, the presence of these films was not as evident. The size range of fibrils and the appearance of the dense CNF films can be seen in the images obtained with higher magnification (right column in Fig. 4). In Fig. 4e the larger size range is evident, including fibrils of the kraft MFC with diameters up to a few hundred nanometres. Silicon 
Fig. 4 SEM images of a a reference sheet and sheets with the addition of $15 \mathrm{wt} \%$ of $\mathbf{b}$ carboxymethylated $\mathrm{CNF}$, $\mathbf{c}$ periodate-oxidised CNF, d dopamine-grafted CNF and e kraft MFC. The left-hand column shows low-magnification images (scale bar equal to $100 \mu \mathrm{m}$ ) and the right-hand column shows high-magnification images (scale bar equal to $2 \mu \mathrm{m})$ (a)

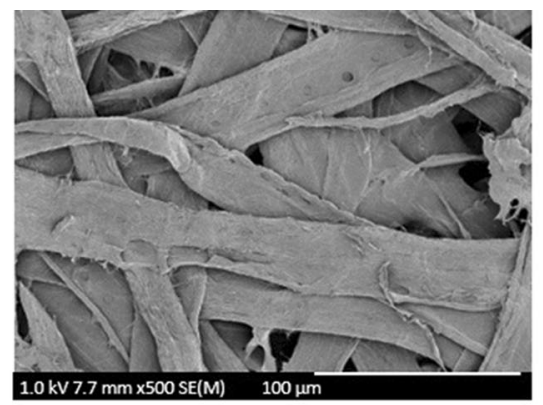

(b)
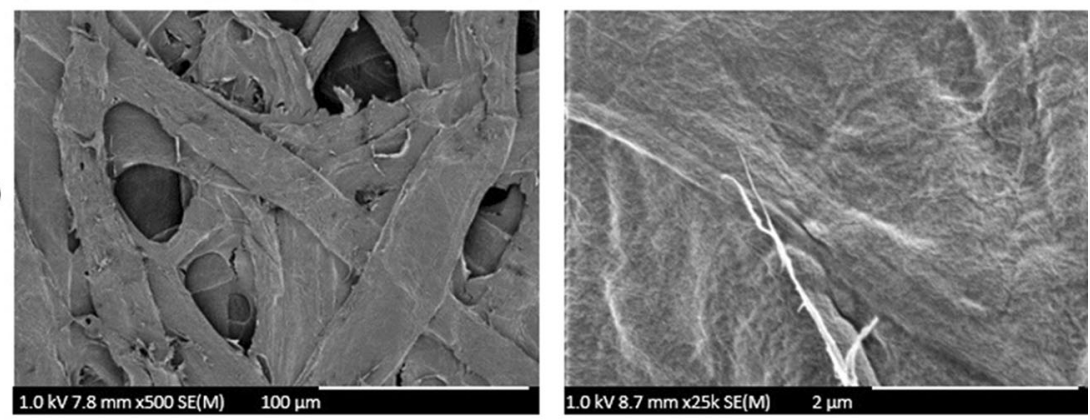

(c)
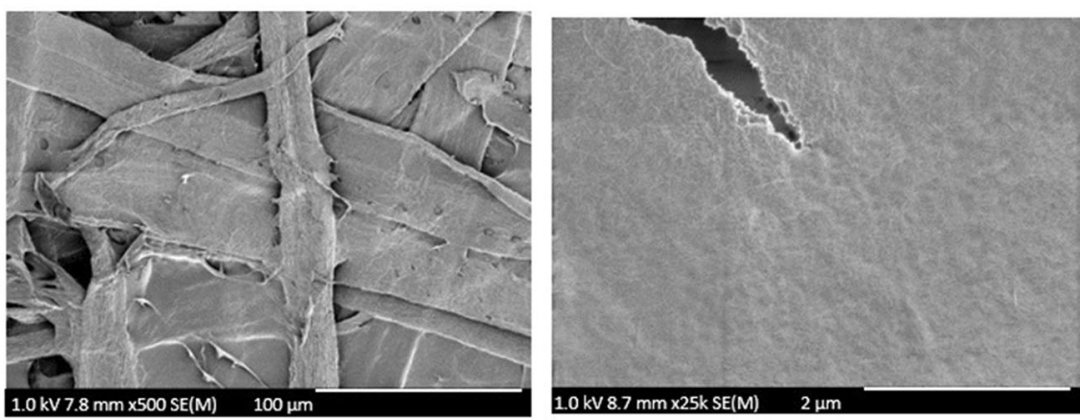

(d)
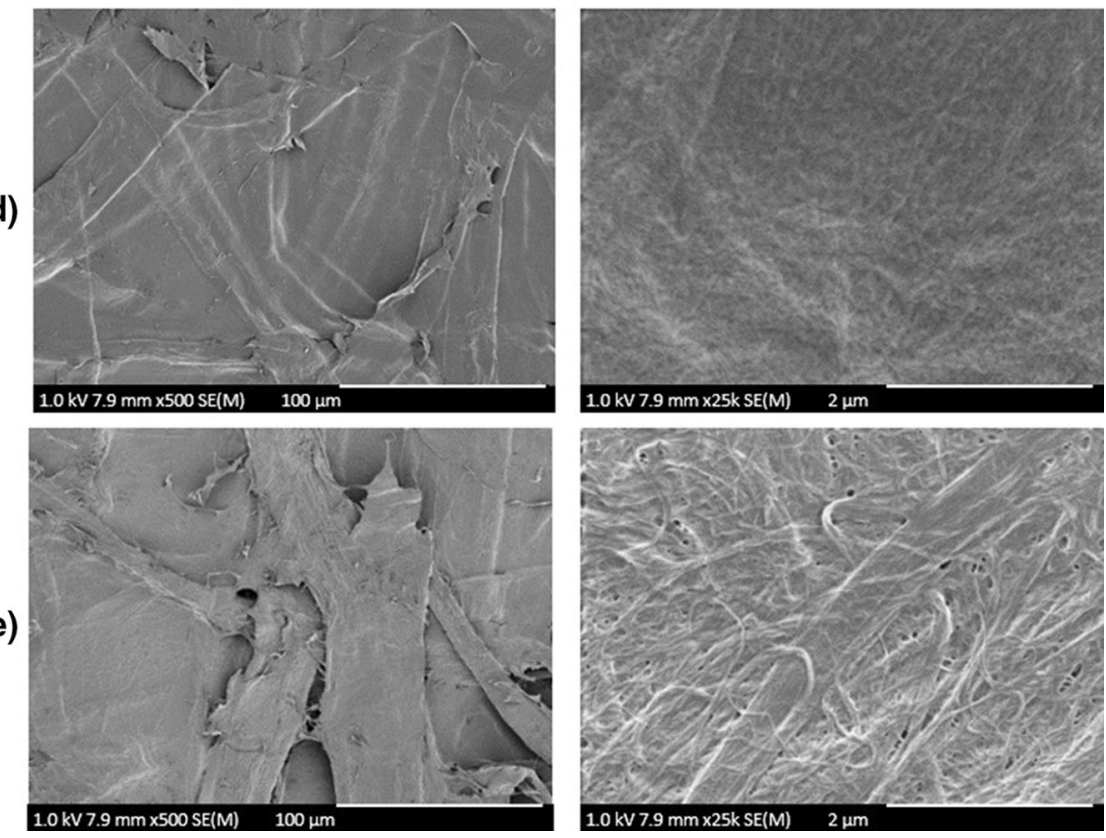
surfaces, with a layer of pre-adsorbed PVAm followed by adsorption of CNFs, were also investigated by SEM in order to separately investigate whether film formation also occurs in the absence of fibres. For the periodate-oxidised CNFs, in contrast to for the other fibrils, no individual fibrils could be seen. The fibrils and the polyelectrolyte instead formed aggregated networks on the surface, as can be seen in Fig. 5.

\section{Mechanical properties of handsheets}

The mechanical properties of paper are naturally strongly dependent on the sheet density (i.e. to the approximate number of fibre-fibre joints per volume). It is therefore important to determine the effect that the addition of CNFs and polyelectrolytes has on the density of the prepared papers. The densities of the paper sheets prepared with and without addition of retention aids (PVAm or pDADMAC) and CNFs are presented in Fig. 6. In the presence of PVAm, the densities of sheets prepared with dopamine-grafted CNFs and periodate-oxidised CNFs are lower than those made in the absence of a retention aid.

The tensile strength data of the sheets are presented in Fig. 7. To make it possible to compare the improvements upon addition of CNFs to a fibre beating, the density increase following a beating from 1000 to 10,000 revolutions in a PFI mill is included in the figure. The density increased for all samples containing CNFs but only periodate-oxidised CNFs or dopamine-grafted CNFs gave an improvement significantly better than that achieved by mechanically beating the fibres to similar densities. In the reported density interval for the pulp studied, the increase in tensile strength as a result of beating was $20-30 \%$,

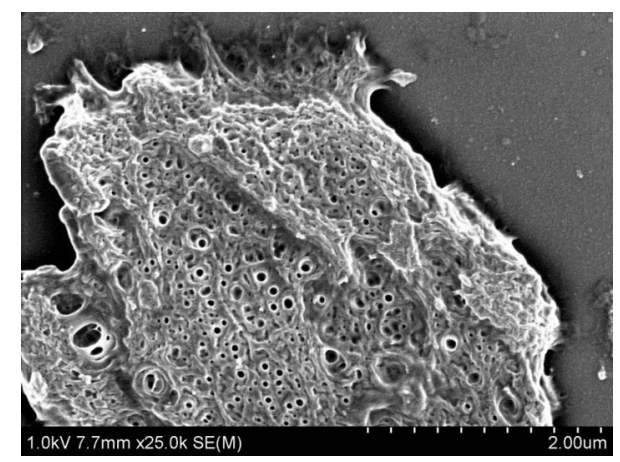

Fig. 5 SEM image showing periodate-oxidised CNFs adsorbed to a silicon surface with a pre-adsorbed PVAm layer with an increase in density of about $15 \%\left(100 \mathrm{~kg} / \mathrm{m}^{3}\right)$. The tensile strength, without retention aid, was highest for the sheets containing dopamine-grafted CNFs, but for the paper sheets with periodate-oxidised CNFs, a greater improvement was achieved when a retention aid was used. With PVAm and 2 wt $\%$ of periodateoxidised CNFs, the tensile strength index increased by $56 \%$ (from 60 to $94 \mathrm{kNm} / \mathrm{kg}$ ) compared to the reference with PVAm and carboxymethylated CNFs. The highest strength, $125 \mathrm{kNm} / \mathrm{kg}$, was obtained with pDADMAC and $15 \mathrm{wt} \%$ of periodate-oxidised CNFs, which corresponds to an increase in tensile strength index of $89 \%$.

As shown in Fig. 8, the Younǵs modulus of the paper sheets increased with increasing addition of CNFs. Some interesting differences were however observed depending on the type of CNF used. Without PVAm, the Young's modulus was higher for sheets with dopamine-grafted CNFs, than for sheets with periodate-oxidised CNFs, increasing by almost $50 \%$ from 5.1 GPa for the reference to 7.2 GPa for the sheet with $15 \mathrm{wt} \%$ dopamine-grafted $\mathrm{CNF}$ addition, i.e. $5 \mathrm{wt} \%$ CNFs in the sheets. In the case of handsheets where kraft MFC films were visible under SEM, the Young's modulus was also significantly increased. With periodate-oxidised CNFs and pDADMAC as retention aid, the sheets became more brittle, with a higher Young's modulus than with PVAm as retention aid (Fig. 9). No effect of further cross-linking between primary amines and aldehydes was thus evident in the dry tensile properties.

The strain-at-break of wood fibres can be increased by beating. In our case, the strain-at-break increased from 1.8 to $3.4 \%$ by an increase from 1000 to 10,000 revolutions in a PFI-mill. The strain-at-break of the paper sheets was also increased by the addition of CNFs. Without PVAm, the strain-at-break increased from $2.6 \%$ for the reference to $4.0 \%$ with the addition of $15 \mathrm{wt} \%$ dopamine-grafted CNFs. Periodate-oxidised CNFs also helped to increase the extensibility of the paper sheets, especially together with PVAm.

The wet tensile strength index is shown in Fig. 10. All additions of CNFs, as well as the addition of PVAm alone, increased the wet strength, but the increase was most pronounced for the modified CNFs, especially the periodate-oxidised CNFs added together with PVAm; with a $15 \mathrm{wt} \%$ addition, the wet tensile index increased from 2.2 to $29.7 \mathrm{kNm} / \mathrm{kg}$, i.e. a more than tenfold increase. Perhaps more 

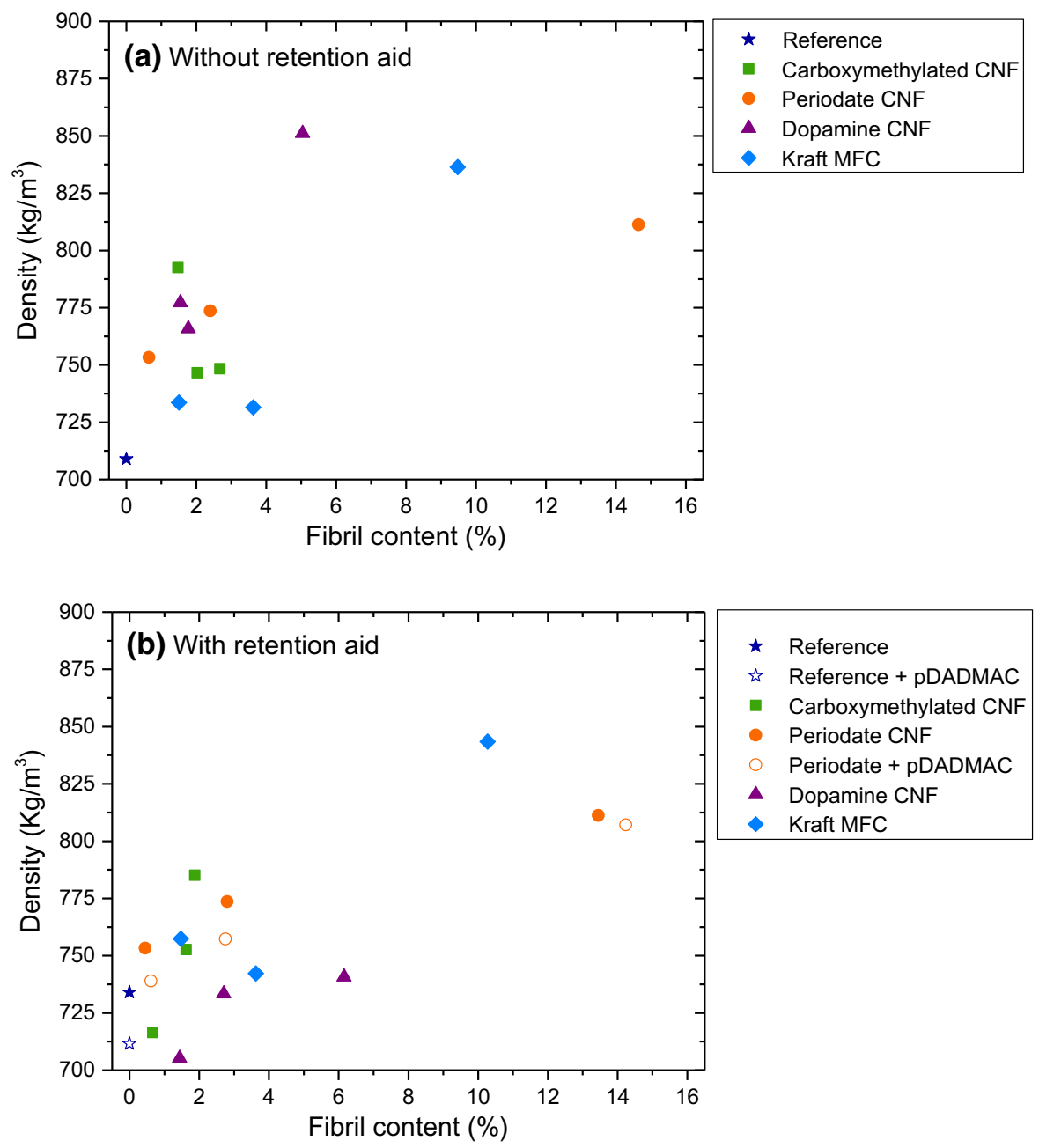

Fig. 6 Density of handsheets as a function of the gravimetrically determined fibril content. PVAm was used as retention aid for all types of CNFs. pDADMAC was also used as a retention aid together with the periodate-oxidised CNFs (open circles)

interestingly, already with $2 \mathrm{wt} \%$ of periodate-oxidised CNFs (with PVAm), the sheets could be considered "wet strong" since more than $10 \%$ of the dry strength was retained in the wet state. To elucidate the importance of these presumed covalent crosslinks, paper sheets were made with pDADMAC, which contains quaternary amines (in contrast to the primary amines in PVAm), as retention aid and periodate-oxidised CNFs. The wet strength also increased with the addition of pDADMAC, although the improvement was only about $50 \%$ of what was obtained with PVAm. It is also worth noting that a significant increase in wet tensile strength index was also observed when periodate-oxidised CNFs were added without any retention aid.
To study the effect of the interaction between the retention aid and the periodate-oxidised CNFs, films were made by mixing periodate-oxidised CNFs and retention aid (PVAm or pDADMAC). As can be seen in Table 2, there was no significant difference in the strain-at-break or in the stiffness of the films, with or without amine-containing polymer. In the presence of the pDADMAC the tensile strength decreased.

\section{Discussion}

The density increase shown in Fig. 6 is well in agreement with the available literature, which shows that an increase in density is indeed usually reported 

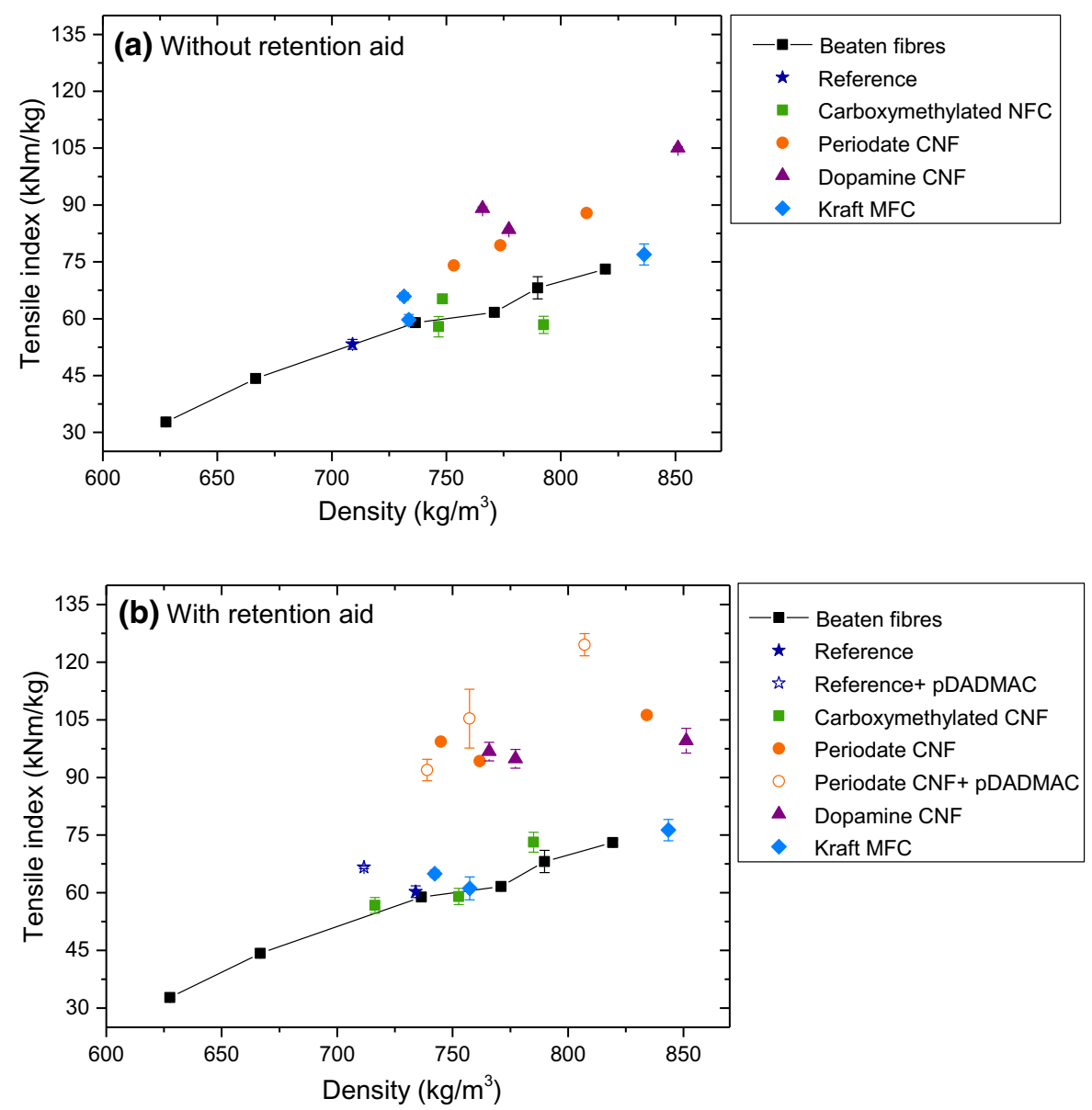

Fig. 7 Tensile strength index of sheets with CNFs; a without and $\mathbf{b}$ with retention aid (PVAm or, if indicated, pDADMAC) as a function of sheet density

when CNFs are added during papermaking. Eriksen et al. (2008) showed an increase in density of $4-30 \%$ in handsheets made of thermomechanical pulp when $4 \%$ MFC was added. The density increase was larger the smaller the particle size. Sehaqui et al. (2013) prepared handsheets with $10 \%$ CNFs mixed with fibres subjected to different beating revolutions. Nonbeaten fibres showed an increase in density of $30 \%$, while after 1000 revolutions the density increased by $6 \%$. For higher degrees of beating, 2000 and 4000 revolutions, no increase in density was observed, but nor was there any improvement in tensile strength index. Rezayati Charani et al. (2013) produced MFC from unbleached kraft Kenaf and Scots Pine that were added during papermaking. After addition of 2-10\% MFC together with $0.1-0.2 \%$ cationic polyacrylamide, the density increased by $20 \%$.
We report that the retention aids do not generally significantly increase the fibril content in the prepared hand sheets. Instead, a common feature of the MFC, the dopamine-grafted CNFs and the periodate-oxidised CNFs is their greater size or higher degree of aggregation which improves their retention during sheet forming: The retention of the highly charged and well dispersed unmodified carboxymethylated CNFs had the lowest retention. The high charge density of the carboxymethylated CNFs probably has a negative effect on the retention due to the strong repulsion between individual fibrils and also between the fibres, which hinders entanglement and network formation. In contrast, the retention is high for the kraft MFC where the retention is believed to benefit from the larger size and lower charge density of the MFC. This suggests that the retention of the kraft MFC is 

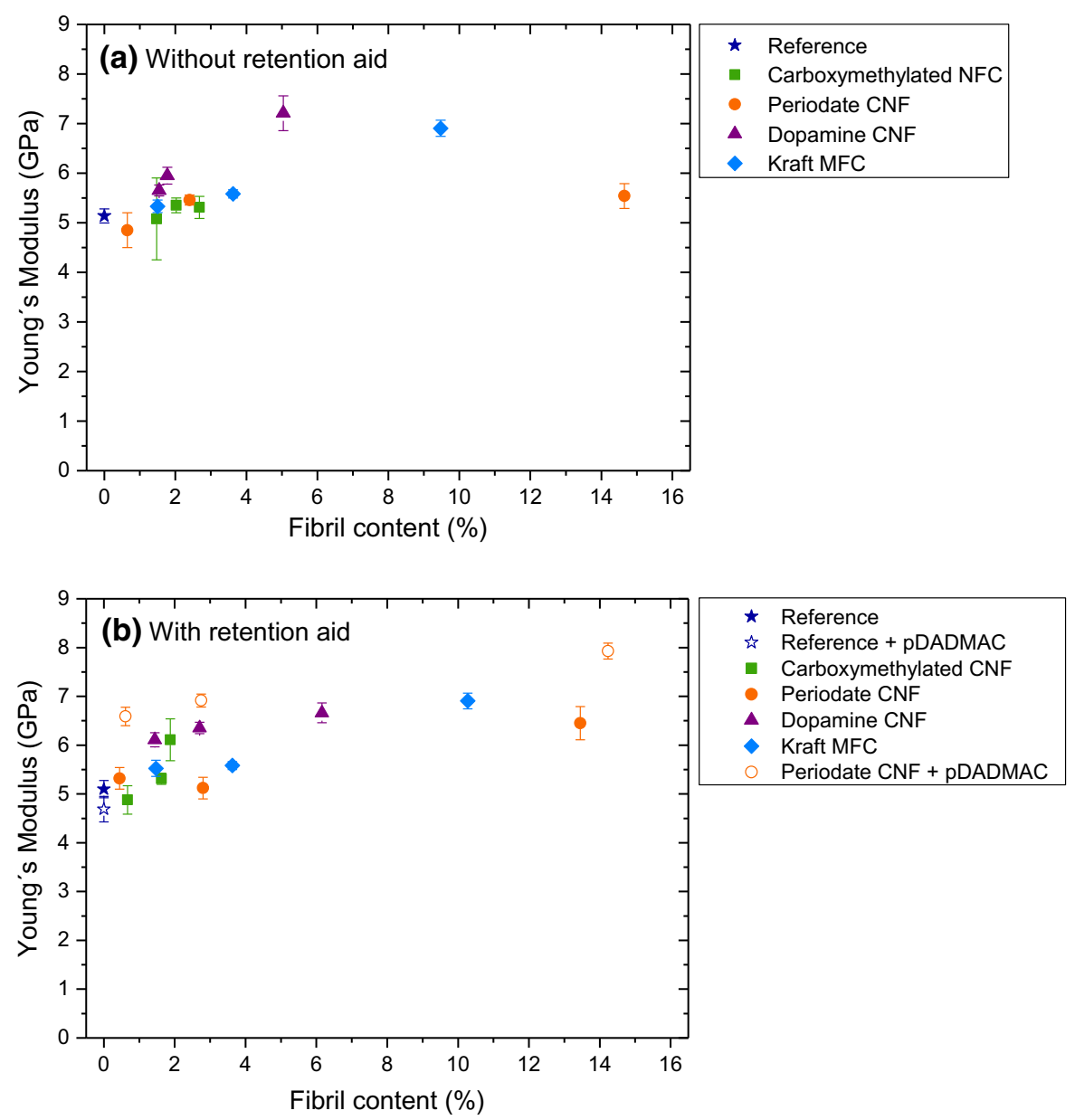

Fig. 8 Young's modulus of sheets with differently modified CNFs; a without and b with retention aid (PVAm and pDADMAC)

dominated by interlocking and entanglement between the MFC particles and the macroscopic fibres. The decrease in surface charge of the periodate-oxidised and dopamine-grafted CNFs compared with the carboxymethylated CNFs can probably be explained both by an aggregation of the modified fibrils and a loss of the carboxyl groups following the dopamine modification and due to some loss of material during periodate oxidation (Larsson et al. 2014). It has earlier been shown by Karabulut et al. (2012) that the modified dopamine-grafted CNFs shows an association to larger complexes but no macroscopic flocculation. A high film-forming ability, of the kraft MFC but particularly the dopamine-grafted CNFs, which was observed by SEM, was also supported by the fact that the dewatering time increased significantly when kraft MFC was added and even more when dopamine- grafted CNFs were added, compared with the reference and the sheets containing periodate-oxidised CNFs which were easily dewatered. It can hence be suggested that the retention of the CNFs is due to their entanglement and filtration (Bergström et al. 1999) during sheet preparation and also due to the ability for association in the case of the dopamine-grafted CNFs (Lee et al. 2007a).

The addition of retention aids is, however, believed to have influenced the position and also the association of fibrils upon adsorption and hence the properties of the final handsheets. In the presence of PVAm, the densities of sheets prepared with dopamine-grafted CNFs and periodate-oxidised CNFs are lower than those made in the absence of a retention aid. This may be explained by the hypothesis that, when PVAm is present, the fibrils are more prone to attach to the fibre 

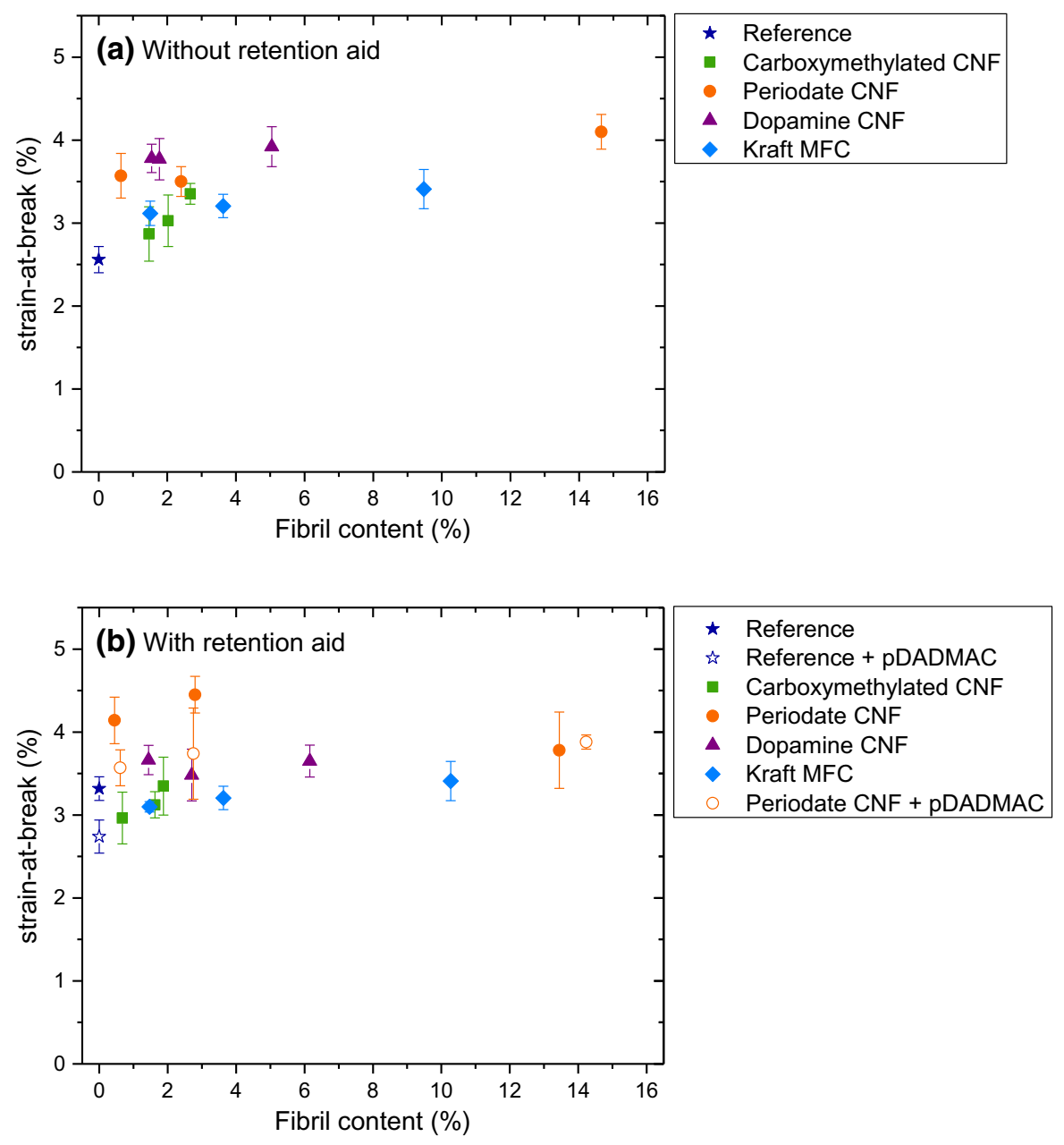

Fig. 9 Strain-at-break of sheets with differently modified CNFs; a without and $\mathbf{b}$ with retention aid (PVAm or pDADMAC)

surface already before dewatering than in the pores between the fibres during dewatering, in contrast to the situation when the fibre surface is untreated and negatively charged and little polyelectrolyte-assisted CNF adsorption take place. The presence of periodateoxidised CNFs on the fibre surfaces is supported by the retained porous structure shown in the SEM images (see Fig. 4) and the higher dewatering rate compared to that of the sheets with dopamine-grafted CNFs and kraft MFC. However, Larsson et al. (2013) showed that also after periodate oxidation of fibres, followed by fibrillation and film making, the dewatering time decreases with increasing degree of oxidation.

With commercial dry strength additives the strengthening effect is generally less than that achieved by beating (Lindström et al. 2005). It was concluded by Brodin et al. (2014) that the improvements in tensile strength reported in several previous publications with CNFs and MFC as paper strength additives are identical with what could be achieved by beating the fibres, and this was also observed in the present study for the sheets containing unmodified CNFs and MFC. The present results show that with periodate-oxidised CNFs and dopaminegrafted CNFs this simple relationship is not found. The tensile strengths are in these cases found significantly above the beating curve. The highest dry strengths measured in this study are those of handsheets with the periodate-oxidised fibrils used together with retention aids. With merely a $2 \mathrm{wt} \%$ addition the tensile strength index was increased by $56 \%$ with periodate-oxidised CNFs and PVAm. For a paper with comparable strength without additives, the improvement is almost twice as high as that reported with a 

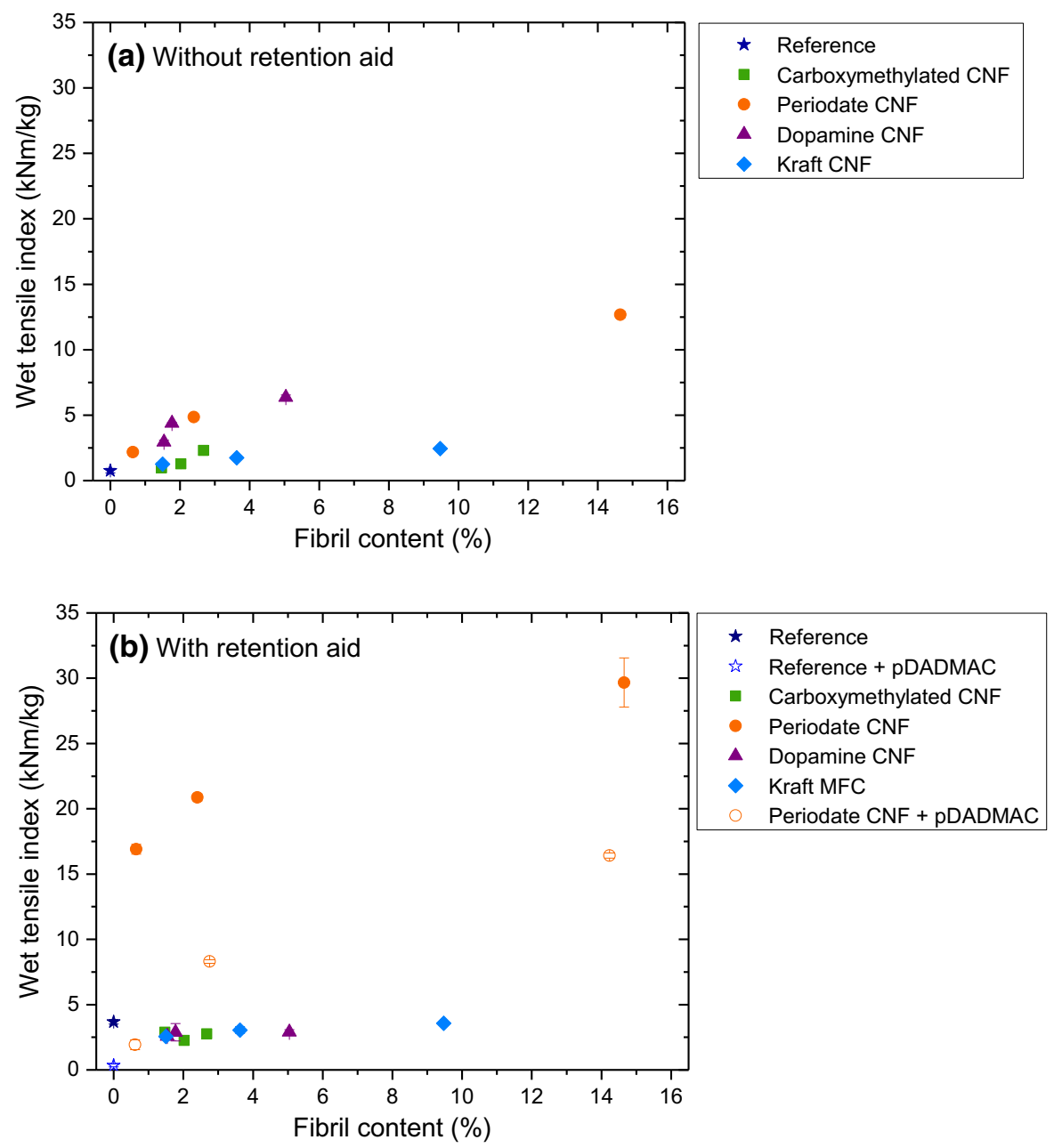

Fig. 10 Wet tensile strength index of sheets with differently modified CNFs; a without and b with retention aid (PVAm and pDADMAC)

Table 2 Mechanical properties of films made from periodate-oxidised CNFs with PVAm and pDADMAC

\begin{tabular}{llll}
\hline Sample name & $\begin{array}{l}\text { Tensile strength } \\
\text { (MPa) }\end{array}$ & $\begin{array}{l}\text { Strain-at-break } \\
(\%)\end{array}$ & $\begin{array}{l}\text { Young's modulus } \\
(\mathrm{GPa})\end{array}$ \\
\hline Periodate-oxidised CNF & $192 \pm 20$ & $2.8 \pm 0.5$ & $8.7 \pm 1.0$ \\
Periodate-oxidised CNF + PVAm & $182 \pm 40$ & $3.0 \pm 0.3$ & $9.7 \pm 1.6$ \\
Periodate-oxidised CNF + pDADMAC & $155 \pm 17$ & $2.9 \pm 0.8$ & $9.3 \pm 1.1$ \\
\hline
\end{tabular}

2 wt\% addition of cationic starch (Lindström et al. 2005). The periodate-oxidised CNFs are believed to form cross-links between the aldehydes formed and available hydroxyls groups and amines, and thereby to significantly strengthen the fibre-fibre joints. While the strength of the handsheets containing periodateoxidized fibrils was increased with addition of a retention aid, it was not further enhanced for handsheets containing dopamine-grafted fibrils with such addition. This may be explained by that the strengthening mechanisms proposed, i.e. cross-linking with fibres and fibrils, of the periodate-oxidised fibrils may be more dependent on the adsorption of fibrils onto the fibre surface, and hence on the presence and nature of 
the polyelectrolyte used, in contrast to the papers containing dopamine-grafted $\mathrm{CNFs}$ which are believed to be strengthened by the formation of dense and strong CNF films, a hypothesis supported by SEM (Fig. 4). The dopamine-grafted CNFs provided the highest tensile strength, Young's modulus and strainat-break among the fibrils, comparing the handsheets made without addition of retention aid, indicating successful stress-release in the papers during loading. The strengthening effect brought about by the created films is remarkable but also comes with an increased dewatering time and care should also be taken due to their sensitivity to air and light, which by oxidation could lead to the formation of quinone structures, bringing yellow, orange or brown discolouration (Zhang and Dryhurst 1993; Zhu et al. 2009; Wei et al. 2013). In the present work this was however not a problem.

The strain-at-break of the handsheets increased with the addition of CNFs, but the major effect was reached already at the lowest addition $(2 \mathrm{wt} \%)$. The sheets were probably strengthened until a limit controlled by the individual fibres was reached. Furthermore, after the addition of CNFs there is a larger bonded area, with more fibrils and there are shorter segments left of the fibres that can be strained.

The dry strength does not seem to be further increased by any cross-linking between the PVAm and periodate-oxidised CNFs and, quite contrary to what was anticipated, the highest strengths were achieved with pDADMAC as retention aid. At the high tensile strength level measured, the fibres themselves may start to show tensile failure and thus become the limiting factor for the overall paper strength, i.e. making it impossible to achieve any improvement by further increasing the fibre joint strength. The results also indicate that for the CNF films the strength induced by the periodate-oxidised CNFs may be high enough to limit additional improvements of the dry strength. The strength improvements reported in this study with periodate-oxidised CNFs, without significant dewatering problems, are significant and indeed promising.

The high wet-strengths reported for the handsheets with periodate-oxidised CNFs indicate the formation of cross-links between aldehydes on the periodateoxidised CNFs and hydroxyl groups present on the pulp fibre, as well as, the formation of imines between the aldehydes and the primary amines from PVAm
(Dash et al. 2012; Larsson et al. 2013). The strong interactions between PVAm and the periodate-oxidised fibrils was also supported both by the rather high wet-strength, up to $30 \mathrm{kNm} / \mathrm{kg}$, and the aggregated structure observed by SEM (Fig. 5) of periodateoxidised CNFs adsorbed on PVAm. Wet-strength was also achieved by the addition of the periodate fibrils, even if not at all as high, both with and without the addition of pDADMAC. Sun et al. (2015) used periodate-oxidised $\mathrm{CNCs}$ and observed an increase in dry tensile index of $33 \%$. The wet tensile strength index increased from 0.7 to $3.1 \mathrm{kNm} / \mathrm{kg}$ when $1.2 \%$ oxidised CNCs was used, improvements comparable to the values reported after the addition of polyethylenimine but an order of magnitude less than that achieved in the present work. No information was given about changes in density, morphology or Younǵs modulus of the sheets that could occur as a result of the addition of nanocrystals. The difference between the results of their study and the current study can probably be attributed to the lower addition of nanocellulose. While Sun et al. (2015) added up to $1.2 \%$ of CNCs without any retention aid, periodateoxidised CNFs in the current study were added from 2 to $15 \%$ and more than $90 \%$ of the periodate-oxidised CNFs was retained in the paper sheets.

\section{Conclusions}

Handsheets were prepared with different micro- and nanofibrillated celluloses added as strength additives and their composition, structure and mechanical properties were determined. With chemically modified CNFs a more significant improvement in tensile strength can be achieved than what can be explained by densification of the sheet, presumably by increasing the joint strength due to chemical cross-links or by the formation of coherent fibrillary networks containing interactive catechol functionalities. The fibrils investigated were carboxymethylated CNFs, periodateoxidised carboxymethylated CNFs and dopaminegrafted carboxymethylated CNFs prepared from bleached dissolving grade fibres and one MFC from unbleached kraft fibres. Different mechanisms for retention and strengthening are proposed for the different CNFs. Dopamine-grafted CNFs gave a high retention even without retention aid and gave a significant increase in tensile strength, but at the price 
of a decrease in dewatering rate, which is suggested to be due to their high propensity to form films. Periodate-oxidised CNFs gave a high retention and high tensile strength and with PVAm the tensile strength index increased by $56 \%$ with as little as $2 \mathrm{wt} \%$ fibrils added. No decrease in dewatering rate was observed following the addition of these fibrils. The aldehyde groups on the periodate-oxidised CNFs are believed to cross-link with the hydroxyls on the fibres, thereby strengthening the fibre-fibre joints. This hypothesis is supported by the fact that the strengthening effect is high and no film formation was observed at lower concentrations. The functional groups of the periodate-oxidised CNFs are also suggested to form cross-links with PVAm, as indicated by the high wet strength which is above $10 \mathrm{kNm} /$ $\mathrm{kg}$ with a $2 \mathrm{wt} \%$ addition and almost $30 \mathrm{kNm} / \mathrm{kg}$ with a $15 \mathrm{wt} \%$ addition. The formation of these cross-links, which affect the wet strength, did however show no apparent effect on the dry strength using the current fibre furnish but considering the high dry strength levels it might be assumed that other factors than the fibre joint strength is controlling the dry paper strength. The kraft MFC, i.e. mechanically disintegrated microfibrils from unbleached pulp with no chemical pre-treatment, had high retention and showed an increase in the Young's modulus, but the addition was accompanied by a longer dewatering time. It is suggested that the larger size of the fibril aggregates and their lower charge density, compared to the carboxymethylated CNFs which had the lowest retention, promotes entanglement with the fibre network and between fibrils. With kraft MFC films covering the pores are visible under SEM, similarly to the dopamine-grafted CNFs, but in contrast to the periodate-oxidised and dopamine-grafted CNFs, the strengthening effect appears to be solely due to densification of the paper.

In conclusion, with chemically modified CNFs as strength additives and with proper anchoring in the paper, it is possible to produce much stronger sheets at low added amounts, in both the dry and wet states, without increasing the density. This demonstrates a potential upgrade of paper products for widespread applications including packaging materials, electrical insulation and wrapping papers.

Acknowledgments The authors thank Dr. Lars Ödberg for helpful comments during the preparation of the manuscript and
Mr. Klas Johansson for skilful assistance with the experimental work. This study was supported by VINNOVA, the Swedish Governmental Agency for Innovation Systems, through BiMaC Innovation Excellence Centre. R. Hollertz acknowledges ABB $\mathrm{AB}$ and The Swedish Energy Agency for financial support through the ELEKTRA program.

Open Access This article is distributed under the terms of the Creative Commons Attribution 4.0 International License (http:// creativecommons.org/licenses/by/4.0/), which permits unrestricted use, distribution, and reproduction in any medium, provided you give appropriate credit to the original author(s) and the source, provide a link to the Creative Commons license, and indicate if changes were made.

\section{References}

Ahola S, Österberg M, Laine J (2008) Cellulose nanofibrilsAdsorption with poly(amideamine) epichlorohydrin studied by QCM-D and application as a paper strength additive. Cellulose 15:303-314. doi:10.1007/s10570-007-9167-3

Azeredo HMC, Rosa MF, Mattoso LHC (2015) Nanocellulose in bio-based food packaging applications. Ind Crops Prod. doi:10.1016/j.indcrop.2016.03.013

Berglund LA, Peijs T (2010) Cellulose Biocomposites-from bulk moldings to nanostructured systems. MRS Bull 35:201-207. doi:10.1557/mrs2010.652

Bergström L, Torbjörn Dahlfors SS, Arwin H, Ödberg L (1999) Spectroscopic ellipsometry characterisation and estimation of the Hamaker constant of cellulose. Cellulose 6:1-13. doi:10.1023/A:1009250111253

Brodin FW, Gregersen ØW, Syverud K (2014) Cellulose nanofibrils: challenges and possibilities as a paper additive or coating material-a review. Nord Pulp Pap Res J 29:156-166. doi:10.3183/NPPRJ-2014-29-01-p156-166

Dash R, Elder T, Ragauskas AJ (2012) Grafting of model primary amine compounds to cellulose nanowhiskers through periodate oxidation. Cellulose 19:2069-2079. doi:10.1007/ s10570-012-9769-2

Eriksen Ø, Syverud K, Gregersen $\varnothing$ (2008) The use of microfibrillated cellulose produced from kraft pulp as strength enhancer in TMP paper. Nord Pulp Pap Res J 23:299-304. doi:10.3183/NPPRJ-2008-23-03-p299-304

Fessenden RJ, Fessenden JS (1986) Organic chemistry, 3rd edn. Wadsworth Inc, Belmont

Hamedi M, Karabulut E, Marais A et al (2013) Nanocellulose aerogels functionalized by rapid layer-by-layer assembly for high charge storage and beyond. Angew Chem Int Ed 52:12038-12042. doi:10.1002/anie.201305137

Hietala M, Ämmälä A, Silvennoinen J, Liimatainen H (2016) Fluting medium strengthened by periodate-chlorite oxidized nanofibrillated celluloses. Cellulose 23:427-437. doi:10.1007/s10570-015-0801-1

Hubbe MA, Rojas OJ, Lucia LA, Sain M (2008) Cellulosic nanocomposites: a review. BioResources 3:929-980

Jackson EL, Hudson CS (1937) Application of the cleavage type of oxidation by periodic acid to starch and cellulose. J Am Chem Soc 59:2049-2050 
Karabulut E, Pettersson T, Ankerfors M, Wågberg L (2012) Adhesive layer-by-layer films of carboxymethylated cellulose nanofibril-dopamine covalent bioconjugates inspired by marine mussel threads. ACS Nano 6:4731-4739. doi:10.1021/nn204620j

Kumar V, Elfving A, Koivula H et al (2016) Roll-to-roll processed ellulose nanofiber coatings. Ind Eng Chem Res 55:3603-3613. doi:10.1021/acs.iecr.6b00417

Larsson PA, Gimåker M, Wågberg L (2008) The influence of periodate oxidation on the moisture sorptivity and dimensional stability of paper. Cellulose 15:837-847. doi:10. 1007/s10570-008-9243-3

Larsson PA, Kochumalayil JJ, Wågberg L (2013) Oxygen and water vapour barrier films with low moisture sensitivity fabricated from self-cross-linking fibrillated cellulose. In: The pulp and paper research fundamental research society, 15 th fundamental research symposium. Lancashire, pp 851-866

Larsson PA, Berglund LA, Wågberg L (2014) Highly ductile fibres and sheets by core-shell structuring of the cellulose nanofibrils. Cellulose 21:323-333. doi:10.1007/s10570013-0099-9

Lavoine N, Desloges I, Bras J (2014) Microfibrillated cellulose coatings as new release systems for active packaging. Carbohydr Polym 103:528-537. doi:10.1016/j.carbpol. 2013.12.035

LeBel RG, Schwartz RW, Sepall O (1968) A novel approach to dimensional stabilization of paper. Tappi 51:79A-84A

Lee H, Scherer NF, Messersmith PB (2006) Single-molecule mechanics of mussel adhesion. Proc Natl Acad Sci 103:12999-13003. doi:10.1073/pnas.0605552103

Lee H, Dellatore SM, Miller WM, Messersmith PB (2007a) Mussel-inspired surface chemistry for multifunctional coatings. Science 318:426-430

Lee H, Lee BP, Messersmith PB (2007b) A reversible wet/dry adhesive inspired by mussels and geckos. Nature 448:338-341. doi:10.1038/nature05968

Lindström T, Wågberg L, Larsson T (2005) On the nature of joint strength in paper: a review of dry and wet strength resins used in paper manufacturing. In: Advances in paper science and technology: 13th fundamental research symposium. Cambridge, pp 457-562

Nyström G, Marais A, Karabulut E et al (2015) Self-assembled three-dimensional and compressible interdigitated thinfilm supercapacitors and batteries. Nat Commun 6:7259. doi:10.1038/ncomms8259

Okahisa Y, Yoshida A, Miyaguchi S, Yano H (2009) Optically transparent wood-cellulose nanocomposite as a base substrate for flexible organic light-emitting diode displays. Compos Sci Technol 69:1958-1961. doi:10.1016/j. compscitech.2009.04.017

Page DH (1969) A theory for the tensile strength of paper. Tappi 52:674-681

Rezayati Charani P, Dehghani-Firouzabadi M, Afra E et al (2013) Production of microfibrillated cellulose from unbleached kraft pulp of Kenaf and Scotch Pine and its effect on the properties of hardwood kraft: microfibrillated cellulose paper. Cellulose 20:2559-2567. doi:10.1007/ s10570-013-9998-z

Sehaqui H, Zhou Q, Berglund LA (2013) Nanofibrillated cellulose for enhancement of strength in high-density paper structures. Nord Pulp Pap Res J 28:182-189. doi:10.3183/ NPPRJ-2013-28-02-p182-189

Spoljaric S, Salminen A, Dang Luong N et al (2014) Nanofibrillated cellulose, poly(vinyl alcohol), montmorillonite clay hybrid nanocomposites with superior barrier and thermomechanical properties. Polym Compos 35:1117-1131. doi:10.1002/pc.22759

Stamm AF (1959) Dimensional stabilization of paper by catalyzed heat treatment and cross-linking with formaldehyde. Tappi 42:44-50

Sun B, Hou Q, Liu Z, Ni Y (2015) Sodium periodate oxidation of cellulose nanocrystal and its application as a paper wet strength additive. Cellulose 22:1135-1146. doi:10.1007/ s10570-015-0575-5

Taipale T, Österberg M, Nykänen A et al (2010) Effect of microfibrillated cellulose and fines on the drainage of kraft pulp suspension and paper strength. Cellulose 17:1005-1020

Turbak AF, Snyder FW, Sandberg KR (1983) Microfibrillated cellulose, a new cellulose product: properties, uses, and commercial potential. J Appl Polym Sci Appl Polym Symp 37:815-827

Wågberg L, Björklund M (1993a) On the mechanism behind wet strength development in papers containing wet strength resins. Nord Pulp Pap Res J 8:053-058. doi:10.3183/ NPPRJ-1993-08-01-p053-058

Wågberg L, Björklund M (1993b) Adsorption of cationic potato starch on cellulosic fibres. Nord Pulp Pap Res J 8:399-404

Wågberg L, Ödberg L, Glad-Nordmark G (1989) Charge determination of porous substrates by polyelectrolyte adsorption. Nord Pulp Pap Res J 4:71-76

Wågberg L, Decher G, Norgren M et al (2008) The build-up of polyelectrolyte multilayers of microfibrillated cellulose and cationic polyelectrolytes. Langmuir 24:784-795. doi:10.1021/la702481v

Weatherwax RC, Caulfield DF (1978) The pore structure of papers wet stiffened by formaldehyde crosslinking. II. Results from nitrogen sorption. J Colloid Interface Sci 67:506-515. doi:10.1016/0021-9797(78)90241-2

Wei H, Ren J, Han B et al. (2013) Stability of polydopamine and poly(DOPA) melanin-like films on the surface of polymer membranes under strongly acidic and alkaline conditions. Colloids Surf B Biointerfaces 110:22-28. doi:10.1016/j. colsurfb.2013.04.008

Zeronian SH, Hudson FL, Peters RH (1964) The mechanical properties of paper made from periodate oxycellulose pulp and from the same pulp after reduction with borohydride. Tappi 47:557-564

Zhang F, Dryhurst G (1993) Oxidation chemistry of dopamine: possible insights into the age-dependent loss of dopaminergic nigrostriatal neurons. Bioorg Chem 21:392-410

Zhao H, Heindel ND (1991) Determination of degree of substitution of formyl groups in polyaldehyde dextran by the hydroxylamine hydrochloride method. Pharm Res 8:400-402

Zhu LP, Yu JZ, Xu YY et al. (2009) Surface modification of PVDF porous membranes via poly(DOPA) coating and heparin immobilization. Colloids Surf B Biointerfaces 69:152-155. doi:10.1016/j.colsurfb.2008.11.011 